\title{
Study the Effect of Weight Loss in Improvement of Hepatic Fibrosis in Patients with Chronic HCV
}

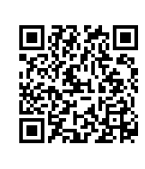

\author{
Khaled Metwally*, Eman Abdelsameea and Tamer Refaat \\ Liver Unit, University of Menoufyia, Egypt
}

Submission: December 11, 2018; Published: January 11, 2019

"Corresponding author: Khaled Metwally, Liver Unit, National Liver Institute, University of Menoufyia, Shebeen El-Kom, Menofia Governorate, Egypt

Abstract

Background: Liver fibrosis considered as a reversible disease, but curing the primary hepatic disease, sometimes, doesn't mean fibrosis improvement. Steatosis could be one of the reasons responsible for this failure. Weight loss has been shown to improve fibrosis, but few data is available from Egypt.

Objective: to test the effect of weight reduction on the degree of fibrosis improvement in patients with chronic hepatitis C (CHC). Methods: Adult patients (> 18 years) were recruited from hepatitis Cout patient's clinic, National Liver Institute (NLI), University of Menoufyia, from 2016 to 2018.

Results: Thirty CHC patients with moderate and severe steatosis, who were initially assessed by liver biopsy and Transient elastography (TE) for their fibrosis stage, were followed up by Transient elastography after losing $>10 \%$ of their weight. Median age was 44.7 years $(29-59$ years) and $50 \%$ were men. The degree of fibrosis and its values improved with the significant weight loss ( $\mathrm{p}<0.01$ for both).

Conclusion: Weight reduction is associated with improvement of hepatic fibrosis in patient with CHC.

Keywords: Fibrosis; Weight loss; Transient elastography; HCV; Steatosis

Abbreviations: CHC: Chronic Hepatitis C; NLI: National Liver Institute; TE: Transient Elastography; NAFLD: Nonalcoholic Fatty Liver Disease; N: Number, SD: Standard Deviation, BMI: Body Mass Index; ALT: Alanine Aminotransferase, AST: Aspartate Aminotransferase, RNA: Ribonucleic Acid, INR: International Normalized Ratio, kPa: Kilopascal

\section{Introduction}

Obesity and its direct consequence, nonalcoholic fatty liver disease (NAFLD), rates are increasing dramatically worldwide, and steatosis becomes one of the most common hepatic histological findings [1]. It was found to be associated with liver fibrosis especially in chronic hepatitis C (CHC) with positive correlation between its grade and the fibrosis stage [2,3]. Liver fibrosis is a dynamic progressive process as long as the hepatic injurious stimulus continues unopposed. It was considered irreversible in the past, but the current studies showed that fibrosis [4-6], and even cirrhosis [7,8] in some series, could be reversible diseases. Our study aimed to compare the degree of hepatic fibrosis in overweight patients with CHC before and after weight loss achieved by diet and exercise, as it is considered the standard treatment for steatosis $[9,10]$.

\section{Methods}

Adult patients ( $>18$ years) were recruited from hepatitis $\mathrm{C}$ clinic, National Liver Institute (NLI), University of Menoufyia, from january2016 to May 2018. Standard available treatment at that time was pegylated interferon with ribavirin. The assessment process necessitates doing liver biopsy and transient elastography (TE). The NLI protocol asked the patient with moderate or severe steatosis to lose at least $10 \%$ of his weight, based on food diet and practicing exercises, to improve the response rate to treatment. FibroScan was done again to reassess the patient's hepatic fibrosis stage after losing weight without the need for re-biopsy. Our retrospective study was conducted on those patients who succeeded to lose the desired weight. We reviewed patients' records and we had thirty patients to be involved in the study after excluding files with incomplete data and patients with $\mathrm{BMI}>40 \mathrm{~kg} / \mathrm{m}^{2}$, as that could affect the FibroScan result.

Our study was approved from the ethical committee, NLI, University of Menoufyia. Height and weight were recorded while BMI was calculated as defined by WHO [11]: bodyweight in kilograms divided by height in meters squared. Liver function evaluation was done by the available data of clinical examinations and laboratory tests.

All liver biopsy specimens were analyzed by one experienced pathologist blinded to the clinical data according to METAVIR scoring system for assessment of fibrosis stage [12]. Steatosis was categorized by visual assessment as: if steatosis presents 


\section{Advanced Research in Gastroenterology \& Hepatology}

in $1-10 \%$ of hepatocytes [mild]; in $11-30 \%$ [moderate]; and 31$100 \%$ [severe].

\section{Transient elstography}

It was performed using the FibroScan $₫$ apparatus (Echosens, Paris, France), with 5- $\mathrm{MHz}$ transducer. The fibrosis grading score used was: $\mathrm{F} 0=0-2.9 \mathrm{kPa} ; \mathrm{F} 1=3-5.9 \mathrm{kPa} ; \mathrm{F} 2=6-8.9 \mathrm{kPa}$; $\mathrm{F} 3=9-16.9 \mathrm{kPa}$; and $\mathrm{F} 4=17-75 \mathrm{kPa}$ (results were expressed in kilopascals) [13-15].

\section{Statistical analysis}

Data was statistically analyzed using SPSS version 21 for windows and for all the analysis a $\mathrm{p}$ value $<0.05$ was considered statistically significant. Data are shown as mean, range or value. As appropriate, stages of fibrosis were tested against continuously-distributed variables using the Anova test. Chisquared test was used to test two ordinal variables, while paired $t$ test was used for pre and post values of the same variable of the same group of patients.

\section{Results}

Table 1: Descriptive data and patients' characteristics at the beginning of assessment.

\begin{tabular}{|c|c|c|}
\multicolumn{1}{|c|}{ Studied Variables } & $(\mathbf{N}=\mathbf{3 0})$ Mean \pm SD & Range \\
\hline Age & $44.7 \pm 8.9$ & $29-59$ years \\
\hline Male & 15 & \\
\hline Female & 15 & \\
\hline BMI & $33.2 \pm 2.5$ & $27-36.9 \mathrm{~kg} / \mathrm{m}^{2}$ \\
\hline ALT & $49.8 \pm 15.8$ & $22-88 \mathrm{U} / \mathrm{L}$ \\
\hline AST & $49.9 \pm 16.1$ & $19-79 \mathrm{U} / \mathrm{L}$ \\
\hline Albumin & $4.2 \pm 0.4$ & $3.6-4.9 \mathrm{gm} / \mathrm{dl}$ \\
\hline Total bilirubin & $0.7 \pm 0.2$ & $0.3-1.1 \mathrm{mg} / \mathrm{dl}$ \\
\hline Direct bilirubin & $0.2 \pm 0.1$ & $0.03-0.5 \mathrm{mg} / \mathrm{dl}$ \\
\hline INR & $1.1 \pm 0.1$ & $1-1.4$ \\
\hline HCV RNA level & $779.6 \pm 1385.5$ & $17.5-5639.9 \mathrm{IU} / \mathrm{ml} \times 10^{3}$ \\
\hline TE & $13.8 \pm 7.5$ & $6.1-30.8 \mathrm{kPa}$ \\
\hline
\end{tabular}

N: Number; SD: Standard Deviation; BMI 1 or 2: Body Mass Index at the beginning of assessment or after weight reduction; ALT: Alanine Aminotransferase; AST: Aspartate Aminotransferase; RNA: Ribonucleic Acid; INR: International Normalized Ratio; kPa: kilopascal

The present study included 30 patients with CHC with moderate and severe steatosis who were initially assessed by liver biopsy and TE for their fibrosis stage, activity grade and degree of steatosis. After losing $10 \%$ or more of their weight, they were followed up by TE only. Our patients' median age was 44.7 years ( 29 - 59 years) and $50 \%$ were men, Table 1 shows the characteristics of patients. According to the histological examination there were 20 patients with moderate and 10 with severe steatosis. Table 2 shows the frequency of different grades of fibrosis between patients according to Metavir classification. Our results showed great improvement of liver stiffness measured by TE after body weight loss. Table 3 shows the frequency of different grades of fibrosis between patients before and after weight reduction and the significant reversibility of fibrosis after weight reduction ( $\mathrm{p}$ $<0.01)$.

Table 2: Characteristics of patients' liver biopsies

\begin{tabular}{|c|c|c|}
\hline & Frequency & $\%$ \\
\hline \multicolumn{3}{|c|}{ Fibrosis stage } \\
\hline $\mathrm{F} 1$ & 11 & 36.7 \\
\hline $\mathrm{F} 2$ & 9 & 30 \\
\hline F3 & 8 & 26.6 \\
\hline $\mathrm{F} 4$ & 2 & 6.7 \\
\hline \multicolumn{3}{|c|}{ Activity grade } \\
\hline $\mathrm{A} 1$ & 16 & 53.3 \\
\hline $\mathrm{A} 2$ & 13 & 43.3 \\
\hline A3 & 1 & 3.4 \\
\hline \multicolumn{3}{|c|}{ Steatosis degree } \\
\hline No & 0 & 0 \\
\hline Mild & 0 & 0 \\
\hline Moderate & 20 & 66.7 \\
\hline Severe & 10 & 33.3 \\
\hline Total & 30 & 100 \\
\hline
\end{tabular}

Liver stiffness 1: at the beginning of assessment; Liver stiffness 2: after weight reduction

Table 3: Classification according to liver stiffness measured by TE.

\begin{tabular}{|c|c|c|c|c|}
\hline $\begin{array}{c}\text { Stage of } \\
\text { Fibrosis }\end{array}$ & \multicolumn{2}{|c|}{$\begin{array}{c}\text { Liver Stiffness 1 } \\
\text { Number (\%) }\end{array}$} & \multicolumn{2}{c|}{$\begin{array}{c}\text { Liver Stiffness 2 } \\
\text { Number (\%) }\end{array}$} \\
\hline F1 & 0 & $(0 \%)$ & 5 & $(16.70 \%)$ \\
\hline F2 & 9 & $(36.70 \%)$ & 9 & $(30 \%)$ \\
\hline F3 & 10 & $(33.30 \%)$ & 10 & $(33.30 \%)$ \\
\hline F4 & 9 & $(30 \%)$ & 6 & $(20 \%)$ \\
\hline & $\mathrm{P}<0.01$ & & & \\
\hline
\end{tabular}

*Paired t-test

SD: Standard deviation; kPa: kilopascal, BMI 1: Body Mass Index at baseline; BMI 2: Body Mass Index after weight reduction

Table 4: Follow up of BMI and Fibro Scan after the decrease in BMI.

\begin{tabular}{|c|c|c|c|c|}
\hline & Mean & SD & Range & p-value \\
\cline { 1 - 4 } BMI $1 \mathrm{~kg} / \mathrm{m}^{2}$ & 33.23 & 2.5 & $27-36.9$ & \multirow{2}{*}{$<0.01^{*}$} \\
\cline { 1 - 4 } BMI $2 \mathrm{~kg} / \mathrm{m}^{2}$ & 29.05 & 1.92 & $24.2-32.5$ & \\
\cline { 1 - 4 } Fibro Scan $1 \mathrm{kPa}$ & 13.81 & 7.46 & $6.1-30.8$ & \multirow{2}{*}{$<0.01^{*}$} \\
\cline { 1 - 4 } Fibro Scan $2 \mathrm{kPa}$ & 10.98 & 5.57 & $3.8-23.9$ & \\
\hline
\end{tabular}

Table 5: Correlation between TE stages of fibrosis before and after weight loss

\begin{tabular}{|c|c|c|}
\hline \multicolumn{3}{|c|}{ Fibrosis stage 1 } \\
\hline 0.7 & $\mathrm{R}$ & \multirow{2}{*}{ Fibrosis stage 2 } \\
\cline { 1 - 2 }$<0.01$ & $\mathrm{p}$ - value & \\
\hline
\end{tabular}

For statistical reason we tested the FibroScan results of liver stiffness again as values in kPs, to avoid any statistical defect when grouping patients into grades. Table 4 shows descriptive data (mean, standard deviation and range) of BMI and liver stiffness measurements. It shows the highly significant improvement of liver fibrosis after weight loss ( $p<0.01$ ) (Table 5). 


\section{Discussion}

Liver fibrosis reversibility is still a hot issue. Although liver fibrosis is agreed to be a dynamic process depending on the balance between degradation and remodeling of extracellular matrix deposition by metalloproteinase enzymes and their tissue inhibitors, yet the mechanism is not completely understood. For instance, treating the cause of liver disease was thought to improve the ability of liver tissue to reverse fibrosis, but studies showed incomplete or insignificant improvement in some patients [6,7]. This could mean that, there are other co-factors which if treated could improve the healing response.

Increased body weight is well known to increase fat deposition in hepatocytes i.e. steatosis and it was claimed to cause liver fibrosis. Studies showed that decreasing its grade by weight loss achieved through lifestyle modifications (diet and exercise) could improve hepatic fibrosis [16], but few or scarce data are available from Egypt, in spite of the high prevalence of liver disease in our population [17].

In our study we depended on Transient Elastography in the assessment of liver fibrosis as it was proved to be a reliable method to detect significant fibrosis compared to histological assessment of liver tissue $[14,18]$, it measures liver stiffness based on the propagation speed of shear waves with overall diagnostic accuracy reaching 94\% [19].

Our study goal was to test if losing significant weight could improve the degree of fibrosis in Egyptian patients suffering CHC. We included patients with moderate or severe steatosis and compared their TE results before and after losing weight. We used BMI11in the assessment of our patients' weight reduction, and we found a significant decrease in it with mean of $4.18 \mathrm{~kg} /$ $\mathrm{m}^{2} ; \mathrm{p}<0.01$.

Our main result was that there is marked improvement in the degree of fibrosis in the second scan and before starting the treatment of CHC. This could mean that losing weight is an important factor for healing liver fibrosis and it could have an additive effect with treating the main cause of liver injury, hepatitis $\mathrm{C}$ in our case. Our results go with Hickman et al16 who investigated 19 patients using liver biopsy before and after weight reduction and found that it was associated with improvement of fibrosis.

Also, Dixon et al, [20] who investigated the effect of losing significant weight after laparoscopic adjustable gastric band placement on the degree of liver fibrosis and inflammation in patients suffering nonalcoholic fatty liver by doing two liver biopsies, before and after weight loss. They reported that significant weight loss was associated with marked improvement in hepatic necroinflammatory changes and stage of fibrosis.

\section{Conclusion}

Weight loss is important to achieve better improvement in hepatic fibrosis beside the treatment of the primary cause of the liver disease. More work is needed to find out other co-factors which, if treated could improve the response to the standard available treatments.

\section{References}

1. Williams CD, Stengel J, Asike MI, Torres DM, Shaw J, et al. (2011) Prevalence of nonalcoholic fatty liver disease and nonalcoholic steatohepatitis among a largely middle-aged population utilizing ultrasound and liver biopsy: a prospective study. Gastroenterology 140(1): 124-131.

2. Leandro G, Mangia A, Hui J, Fabris P, Rubbia-Brandt L, et al. (2006) Relationship between steatosis, inflammation, and fibrosis in chronic hepatitis C: a meta-analysis of individual patient data. Gastroenterology 130(6): 1636-1642.

3. Zubair A, Mubarik A, Jamal S, Arif A, Khan DA (2009) Correlation of steatosis with fibrosis and necro-inflammation in chronic hepatitis $\mathrm{C}$ infection in the absence of confounding factors. J Coll Physicians Surg Pak 19(7): 417-420.

4. Rockey DC (2016) Liver Fibrosis Reversion After Suppression of Hepatitis B Virus. Clin Liver Dis 20(4): 667-679.

5. Ellis EL, Mann DA (2012) Clinical evidence for the regression of liver fibrosis. J Hepatol 56(5): 1171-1180.

6. Ramachandran P, Iredale JP, Fallowfield JA (2015) Resolution of liver fibrosis: basic mechanisms and clinical relevance. Semin Liver Dis 35(2): 119-131.

7. Manne V, Akhtar E, Saab S (2014) Cirrhosis regression in patients with viral hepatitis B and C: a systematic review. J Clin Gastroenterol 48(9): e76-84.

8. Sohrabpour AA, Mohamadnejad M, Malekzadeh R (2012) Review article: the reversibility of cirrhosis. Aliment Pharmacol Ther 36(9): 824832.

9. Tilg H, Moschen A (2010) Weight loss: cornerstone in the treatment of non-alcoholic fatty liver disease. Minerva Gastroenterol Dietol 56(2): 159-167.

10. Clark JM (2006) Weight loss as a treatment for nonalcoholic fatty liver disease. J Clin Gastroenterol 40(Suppl 1): S39-43.

11. (1995) Physical status: the use and interpretation of anthropometry. Report of a WHO Expert Committee. World Health Organ. Tech Rep Ser 854: 1-452.

12. Bedossa P, Poynard T (1996) An algorithm for the grading of activity in chronic hepatitis C. The METAVIR Cooperative Study Group. Hepatology 24(2): 289-293.

13. Vizzutti F, Arena U, Romanelli RG, Rega L, Foschi M, et al. (2007) Liver stiffness measurement predicts severe portal hypertension in patients with HCV-related cirrhosis. Hepatology 45(5): 1290-1297.

14. Colletta C, Smirne C, Fabris C, Toniutto P, Rapetti R, et al. (2005) Value of two noninvasive methods to detect progression of fibrosis among HCV carriers with normal aminotransferases. Hepatology 42(4): 838845.

15. Nitta Y, Kawabe N, Hashimoto S, Harata M, Komura N, et al. (2009) Liver stiffness measured by transient elastography correlates with fibrosis area in liver biopsy in patients with chronic hepatitis C. Hepatol Res 39(7): 675-684.

16. Hickman IJ, Clouston AD, Macdonald GA, Purdie DM, Prins JB, et al. (2002) Effect of weight reduction on liver histology and biochemistry in patients with chronic hepatitis C. Gut 51(1): 89-94.

17. Kandeel A, Genedy M, El-Refai S, Funk AL, Fontanet A, Talaat M (2017) The prevalence of hepatitis C virus infection in Egypt 2015: implications for future policy on prevention and treatment. Liver Int 37(1): 45-53. 
18. Ziol M, Handra-Luca A, Kettaneh A, Christidis C, Mal F, et al. (2005) Noninvasive assessment of liver fibrosis by measurement of stiffness in patients with chronic hepatitis C. Hepatology 41(1): 48-54.

19. Mobarak L, Nabeel MM, Hassan E, Omran D, Zakaria Z (2016) Real-time elastography as a noninvasive assessment of liver fibrosis in chronic

This work is licensed under Creative Commons Attribution 4.0 License

DOI: 10.19080/ARGH.2019.12.555826 hepatitis C Egyptian patients: a prospective study. Ann. Gastroenterol 29(3): 358-362.

20. Dixon JB, Bhathal PS, Hughes NR, O'Brien PE (2004) Nonalcoholic fatty liver disease: Improvement in liver histological analysis with weight loss. Hepatology 39(6): 1647-1654.

\section{Your next submission with JuniperPublishers will reach you the below assets}

- Quality Editorial service

- Swift Peer Review

- Reprints availability

- E-prints Service

- Manuscript Podcast for convenient understanding

- Global attainment for your research

- Manuscript accessibility in different formats

( Pdf, E-pub, Full Text, audio)

- Unceasing customer service

Track the below URL for one-step submission https://juniperpublishers.com/online-submission.php 